\title{
Weight and Height as limiting characteristics to achieve better performances in Quality CPR in children
}

Anita Luciani ${ }^{1}$, Stefano Gandolfi ${ }^{1}$, Niccolò Grieco², Giuseppe Ristagno ${ }^{3}$, Silvia Scelsi ${ }^{4}$, Federico Semeraro ${ }^{5}$, Andrea Scapigliati ${ }^{6}$

${ }^{1}$ Italian Resuscitation Council Foundation, Bologna, Italy. ${ }^{2}$ Grande Ospedale Metropolitano Niguarda, Milano, Italy. ${ }^{3}$ sstituto di ricerche farmacologiche "Mario Negri" - IRCCS, Milano, Italy. ${ }^{4}$ Pediatric Hospital G. Gaslini, Genoa, Italy. ${ }^{5}$ Maggiore Hospital, Bologna, Italy. ${ }^{6}$ Fondazione Policlinico Universitario A. Gemelli - IRCCS, Roma, Italy.

\section{Purpose of the study}

In June 2017, Italian Resuscitation Council (IRC) participated at the international festival "HaBaWaBa", and organized a 5-day Mass Training to increase CPR skills in youngers.

Three hundred and seven children $(95 \%$ male, age $10.2 \pm 0.8$ years old, BMl $19 \pm 3 \mathrm{~kg} / \mathrm{m} 2$ ) were recruited for this study.

The purpose was to assess their ability to provide high quality CPR on a chest compression only scenario.

\section{Materials and methods}

Resusci Anne (RA) Q-CPR manikins (Laerdal, Norway) with and without feedback (196 children) and Brayden Pro (BP) manikins (Innosonian, South Korea) with feedback (111 children) were used to collect data on CPR quality.

\section{Results}

Results were divided according to children's weight ( $\leq 40 \mathrm{Kg}$ vs. $>40 \mathrm{Kg})$ and height $(<147 \mathrm{~cm}$ vs. $>147 \mathrm{~cm})$. Children were not able to reach and/or maintained the targets for good quality CPR (Table 1 and 2). Nobody achieved a depth of 50-60 mm: mean depth was $39 \pm 6 \mathrm{~mm}$ in the BP group and $31 \pm 8.4 \mathrm{~mm}$ in the RA group $(p<0.001)$. However, Overall Score (OS) of CPR was better in children weighing $>40 \mathrm{~kg}$ compared to lighter ones.

\section{Conclusion}

Our study confirmed that children are not able, due to physical restraints, to achieve target of chest compression depth.

Nevertheless, stratification according to physical characteristics, showed that a greater weight accounted for a better CPR performance.

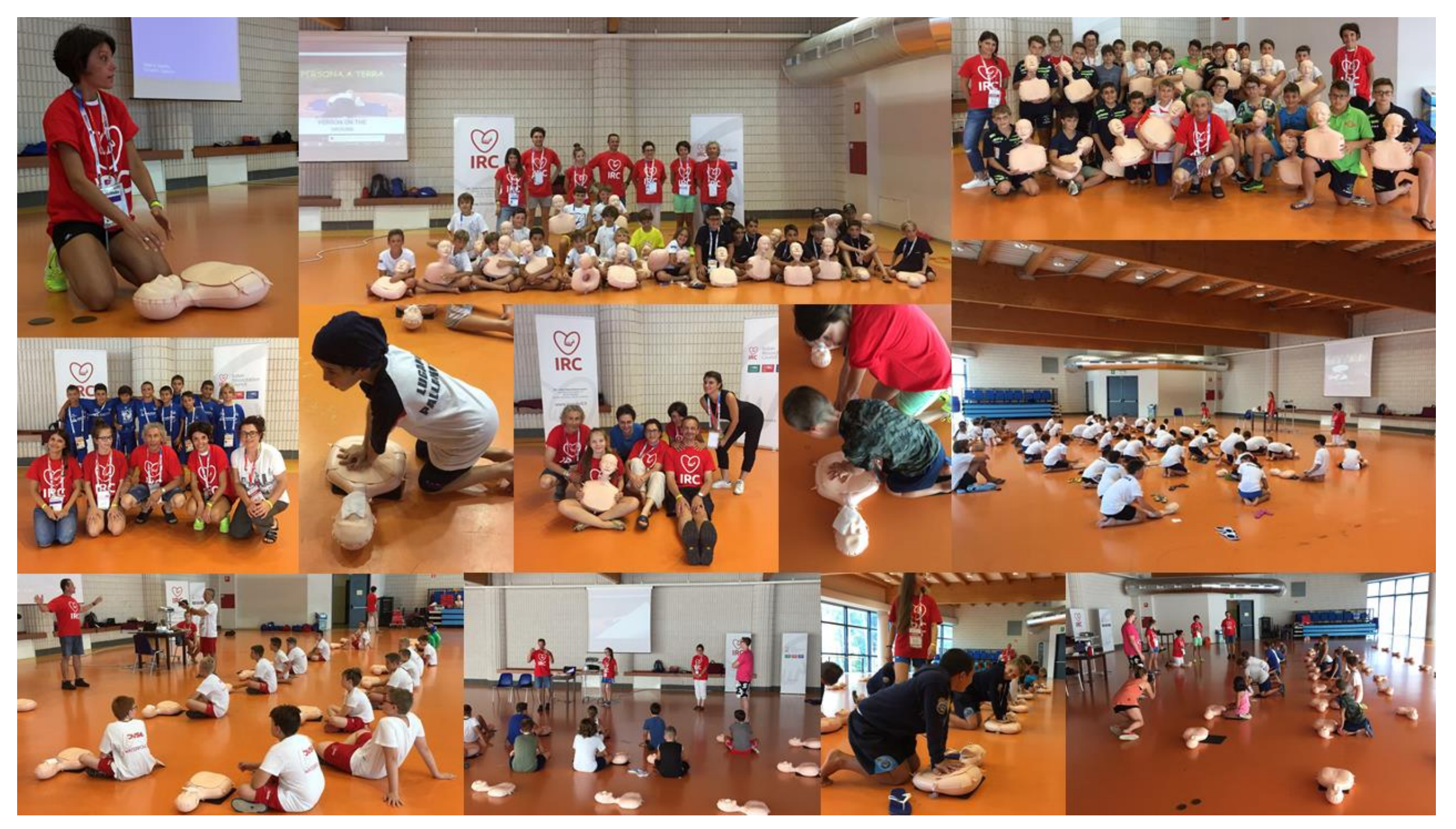

Table 1: summary data of weight

\begin{tabular}{|l|l|l|l|}
\hline & Overall score $\%$ & & \\
\hline Weight & $\leq 40 \mathrm{Kg}$ & $>40 \mathrm{Kg}$ & $\mathrm{p}$ \\
\hline BP $(\mathrm{n}=111)$ & $55.2 \pm 0.2$ & $60.9 \pm 11.2$ & $<0.05$ \\
\hline RA $(\mathrm{Q}-\mathrm{CPR}(\mathrm{n}=196)$ & $41.3 \pm 15.39$ & $51.48 \pm 14.94$ & $<0.0001$ \\
\hline
\end{tabular}

Table 2: summary data of height

\begin{tabular}{|l|l|l|l|}
\hline & Overall score $\%$ & & \\
\hline Height & $\leq 147 \mathrm{~cm}$ & $>147 \mathrm{~cm}$ & $\mathrm{p}$ \\
\hline BP $(\mathrm{n}=111)$ & $56.5 \pm 11$ & $59 \pm 11$ & 0.25 \\
\hline RA $(\mathrm{Q}-$ CPR $(\mathrm{n}=196)$ & $40.35 \pm 14.60$ & $51.63 \pm 15.34$ & $<0.0001$ \\
\hline
\end{tabular}

